\title{
Volumetria hepática computadorizada como método de avaliação e acompanhamento da regeneração hepática após hepatectomia parcial em suínos
}

\section{Computerized liver volume for evaluation and following liver regeneration after partial hepatectomy in swines}

Fábio Augusto de Carvalho, ACBC-PR; Henry Joyeux²; Júlio Cezar U. Coelho, TCBC-PR³; Bernard Sain-Aubert ${ }^{4}$; Philipe Rouanet ${ }^{4}$; Jorge Eduardo Fouto Matias ${ }^{5}$

\section{RE S U M O}

\begin{abstract}
Objetivo: O estudo analisou a volumetria hepática por tomografia axial computadorizada, através de um programa informatizado semi-automático de aquisição e processamento de imagens digitalizadas, como parâmetro de acompanhamento da regeneração hepática em suínos, após hepatectomia parcial. Método: Doze suínos fêmeas, da raça Landrace, jovens, foram distribuídos em 3 grupos, conforme tempo de observação após o procedimento cirúrgico: 5(G5), 10(10) ou 15(G15) dias. Todos foram submetidos à hepatectomia parcial e, posteriormente, após acompanhamento, sacrificados, procedendo-se a retirada do fígado regenerado. A peça da hepatectomia e o fígado regenerado foram pesados e submetidos à realização da tomografia e aferição do volume através do software HEPATO ${ }^{\circledR}$. Para análise estatística foram utilizados os testes nãoparamétricos de Kruskal-Wallis e Wilcoxon. Valores de $p<0,05$ indicaram significância estatística. Resultados: $O$ peso do fígado regenerado foi de: $G 5=434,5 \mathrm{~g}, \mathrm{G} 10=449,25 \mathrm{~g}$ e $\mathrm{G} 15=486,5 \mathrm{~g}), \mathrm{p}=0,592$. A regeneração hepática a partir do peso do fígado foi de $83,58 \%$ (G5), 94,95\% (G10) e 101,63\% (G15), $p=0,197$. O volume do fígado regenerado foi de $403,58 \mathrm{~cm}^{2}(\mathrm{G} 5)$, $450,88 \mathrm{~cm}^{2}$ (G10) e 458,93 $\mathrm{cm}^{2}$ (G15), p=0,941. A regeneração hepática a partir do volume do fígado foi de $74,25 \%$ (G5), 88\% (G10) e $100 \%$ (G15), $p=0,326$. Não houve diferença estatística significativa entre os parâmetros. Conclusão: $A$ avaliação volumétrica por tomografia computadorizada, utilizando um programa informatizado semi-automático de aquisição e processamento de imagens digitalizadas, é método fidedigno para avaliação e acompanhamento da regeneração hepática em suínos, após hepatectomia parcial.
\end{abstract}

Descritores: Regeneração hepática. Tomografia. Hepatectomia. Suínos.

\section{INTRODUÇÃO}

O transplante hepático, na sua modalidade intervivos, é inovação técnica importante e vem sendo realizado por número crescente de centros transplantadores. Para o seu sucesso são fundamentais determinadas avaliações, tais como aferição do volume dos lobos hepáticos e avaliação da anatomia vascular e biliar do fígado do doador. O volume hepático assume grande relevância, pois com base nele pode-se estimar o peso total do fígado no doador, bem como o peso do enxerto a ser implantado no receptor ${ }^{1}$. Os bons resultados se relacionam com volume de enxerto superior a $1 \%$ do peso do receptor, e com preservação de pelo menos 20 a $25 \%$ de parênquima hepático residual no doador. Apesar de inúmeros métodos de avaliação destas variáveis terem sido desenvolvidos, muito poucos são confiáveis para o planejamento de tal procedimento. A avaliação volumétrica do fígado na prática clínica é, de maneira geral, imprecisa e incompleta. Fórmulas desenvolvidas para mensurar o volume do fígado a partir de dados facilmente acessíveis, como idade e peso, apesar de práticas, permitem apenas calcular o volume total aproximado, sem possibilitar a distinção volumétrica entre os lobos hepáticos. Com tecnologias de imagem de alta resolução - tomografia axial computadorizada (TAC) e ressonância nuclear magnética (RNM) - a aferição da volumetria hepática no âmbito do transplante intervivos tornou-se rotineira². Entre-

\footnotetext{
Estudo foi realizado no Laboratório de Cirurgia Experimental, do Departamento de Cirurgia da Faculdade de Medicina de Montpellier, França, e no Programa de Pós-Graduação em Clínica Cirúrgica da Universidade Federal do Paraná.

1 Mestrando do Programa de Pós-Graduação em Clínica Cirúrgica da Universidade Federal do Paraná - UFPR, PR, BR; 2 Professor do Departamento de Cirurgia da Faculdade de Medicina de Montpellier, França; 3 Professor Titular do Departamento de Cirurgia da Universidade Federal do Paraná - UFPR; 4 Professores do Departamento de Cirurgia da Faculdade de Medicina de Montpellier, França; 5 Professor Adjunto do Departamento de Cirurgia da Universidade Federal do Paraná - UFPR, PR, BR.
} 
tanto, na prática diária, ainda há subutilização dos dados fornecidos pelos exames de imagens. A mensuração precisa do volume hepático é possível, mas raramente realizada. As imagens utilizadas para esta aferição são sempre cortes bidimensionais assumindo que a forma volumétrica do objeto a ser medido é uma esfera, o que pode alterar os dados volumétricos. Além disso, o trabaIho de aferição volumétrica exige tempo excessivo por parte do radiologista que, de posse das imagens no computador, deve selecionar cada corte bidimensional, contornando as imagens a serem medidas. O mesmo problema é enfrentado na geração das imagens tridimensionais, que devem passar pelo mesmo processo. Na tentativa de otimizar o uso da TAC e RNM, protocolos de estudos foram desenvolvidos para a pesquisa de programas informatizados de avaliação volumétrica computadorizada, semi-automáticas ou automáticas ${ }^{3}$. Estes programas computadorizados permitem a avaliação do volume hepático em poucos minutos, facilitando o trabalho da equipe médica na aferição volumétrica do fígado.

A utilização de modelos animais para o desenvolvimento desses programas informatizados são de fundamental importância e proporcionam o desenvolvimento de novas tecnologias.

Os estudos em suínos são os mais utilizados, por diversos motivos, entre eles: a anatomia hepática muito similar a dos seres humanos, maior facilidade para se coletar amostras sanguíneas seriadas para avaliação das funções hepáticas e a possibilidade da indução de modelos patológicos, para estudos específicos, como o de suínos com insuficiência hepática fulminante ${ }^{4}$. O presente estudo teve por objetivo avaliar a volumetria hepática aferida por meio de um programa computadorizado semi-automático de aquisição e processamento de imagens digitalizadas de tomografia axial computadorizada como parâmetro fidedigno de detecção e acompanhamento da regeneração hepática em suínos, após uma hepatectomia parcial.

\section{MÉTODO}

O estudo foi realizado no laboratório de Cirurgia Experimental, do Departamento de Cirurgia da Faculdade de Medicina de Montpellier, França, como parte integrante da plataforma de pesquisa médica do Centre Régional de Lutte contre le Câncer (CRLC), de Montpellier; para o desenvolvimento de programas informatizados automáticos para aferição do volume hepático por tomografia axial computadorizada. Todas as fases do estudo foram aprovadas em Comitê de Ética em Pesquisa da Faculdade de Medicina de Montpellier.

\section{Procedimento Experimental}

Foram utilizados 12 suínos fêmeas, da raça Landrace, jovens, com idade entre 4 e 6 meses. Após perí- odo de adaptação, os animais foram submetidos à aferição de peso por intermédio de uma balança calibrada, separados aleatoriamente em 3 grupos, de 4 animais cada, denominados G5, G10 e G15 e submetidos todos à mesma intervenção cirúrgica (hepatectomia parcial do lobo direito) de maneira cega e aleatória. Após jejum de 12 horas, uma solução de $5 \mathrm{~mL}$ de quetamina $(50 \mathrm{mg} / \mathrm{mL}), 1 \mathrm{~mL}$ de midazolan $(5 \mathrm{mg} / \mathrm{mL})$ e $1 \mathrm{~mL}$ de atropina $(1 \mathrm{mg} / \mathrm{mL})$ foi aplicada intramuscular na região cervical. Indução anestésica foi realizada com $5 \mathrm{mg} / \mathrm{kg}$ de fenobarbital através de acesso venoso estabelecido na orelha do animal. Intubação orotraqueal foi realizada com cânula $n^{\circ} 8$, seguida por administração de forane inalatório a $1 \%$ em ventilação mecânica para a manutenção na anestesia. Sob condições de antissepsia cirúrgica, após laparotomia mediana xifopúbica e liberação dos ligamentos hepáticos, procedeu-se ao isolamento e ligadura dos ramos da veia porta para os segmentos VI e VII. O controle vascular intraparenquimatoso dos ramos da veia supra-hepática direita que drenam os segmentos VI e VII foi realizado de acordo com técnica já descrita anteriormente ${ }^{5}$. A peça cirúrgica (segmentos VI e VII do lobo direito) era ressecada, imediatamente pesada em uma balança calibrada, dentro de recipiente com peso pré-determinado, recoberta com gelo picado e levada à sala de tomografia, onde eram realizados os exames de imagem.

Os animais foram sacrificados após determinado número de dias de acordo com a divisão dos grupos: G5 no $5^{\circ}$ dia pós-operatório, $\mathrm{G} 10$ no $10^{\circ}$ e $\mathrm{G} 15$ no $15^{\circ}$. No dia do sacrifício, todos os procedimentos anestésicos realizados no dia da hepatectomia foram repetidos. Em seguida, após abertura da laparotomia, liberação de aderências e injeção endovenosa de $10 \mathrm{~mL}$ de cloreto de potássio à 19,1\%, realizou-se a retirada do fígado remanescente regenerado que foi acondicionado, pesado e encaminhado para estudo tomográfico da mesma maneira com que foi feito para a peça cirúrgica do dia da hepatectomia.

\section{Processamento das Imagens}

Todos os exames de tomografia helicoidal computadorizada foram realizados no setor de radiologia do CRLC, Montpellier, França, em tomógrafo Picker $^{\circledast}$ PQ2000, de $4^{a}$ geração. Após acondicionamento das peças em recipiente de poliestireno, recobertas por gelo picado, para melhorar os contornos das imagens adquiridas, realizou-se então a aquisição dos cortes tomográfico de $5 \mathrm{~mm}$ de espessura, sem injeção de contraste. As imagens bidimensionais do exame tomográfico foram transferidas para um computador através do formato digital DICOM, e serem tratadas pelo programa de informática para avaliação da volumetria das peças cirúrgicas. O software utilizado para a aferição da volumetria hepática $\left(\right.$ HEPATO $^{\circledR}$ ) é um programa multiplataforma de aquisição e processamento de imagens digitalizadas, específico para tratamento de imagens tomográficas do fígado, de forma semi-automática, desenvolvido pelo CRLC, no intuito de auxiliar os pro- 
tocolos de estudo em hepatologia clínica e cirúrgica. Permite otimizar a qualidade das imagens obtidas, fazer a reconstrução tridimensional das estruturas, bem como medir, de forma simples e rápida, o volume de qualquer ponto dentro dos cortes tomográficos com boa confiabilidade e margem de erro menor do que $5 \%{ }^{6}$. As imagens bidimensionais foram agrupadas sob forma de cortes seriados no formato numérico DICOM, para constituir um conjunto de imagens tridimensionais, passíveis de serem analisadas pelo software HEPATO ${ }^{\circledR}$. Em seguida, através de filtros, melhora-se a qualidade das imagens para que tenham contornos mais claros e nítidos. Dentro de um único corte bidimensional, através do mouse seleciona-se a área a ser aferida com contornos coloridos (Figura 1). Uma vez os tecidos identificados, a região 3D correspondente a esta área é automaticamente selecionada sobre todos os outros cortes. Segue-se a reconstrução tridimensional, com a volumetria dos tecidos hepáticos selecionados e não selecionados, simultaneamente. O tempo médio para a realização de todas as etapas foi de aproximadamente 5 minutos. A aferição volumétrica da região a ser estudada aparece automaticamente na tela, permitindo a utilização dos dados obtidos de forma rápida e precisa.

\section{Parâmetros de Estudo}

Os animais foram examinados diariamente no pós-operatório para observação de possíveis complicações clínicas, infecções de ferida operatória e óbitos. Foram analisados os pesos corporais no período pré-operatório e no dia do sacrifício. Avaliaram-se também os pesos totais do fígado no dia da hepatectomia e no dia do sacrifício. No dia da hepatectomia, o peso total do órgão foi estimado a partir do peso corporal do animal, através da fórmula: Peso do fígado $(\mathrm{g})$ = Peso do suíno $(\mathrm{Kg})$ x 27,178.

Para constatar a inexistência de diferença de quantidade de parênquima ressecado durante a hepatectomia entre os grupos de estudo, o peso aferido das peças cirúrgicas no dia da hepatectomia foi utilizado para o cálculo da porcentagem de parênquima ressecado em cada grupo. Para tal, estabeleceu-se a relação porcentual entre o peso da peça cirúrgica e o peso total do fígado estimado no dia da hepatectomia. De maneira similar, a mesma relação porcentual pôde ser estabelecida a partir dos volumes hepáticos no dia da hepatectomia. Para tal, o volume total do fígado foi estimado pela fórmula: Volume da peça cirúrgica (g) x 100 / Porcentagem de ressecção hepática.

Finalmente, a porcentagem de regeneração hepática pôde ser determinada quer seja através do peso quer seja através do volume do fígado, comparando-se a existência ou não de diferenças de avaliação da regeneração entre os dois métodos.

\section{Análise Estatística}

Procedeu-se a tratamento estatístico, de acordo com a natureza dos dados estudados. Para a comparação dos grupos em relação às variáveis do estudo, considerouse o teste não-paramétrico de Kruskal-Wallis. Para a comparação dos momentos inicial e final, considerou-se o teste não-paramétrico de Wilcoxon. Valores de $p<0,05$ indicaram significância estatística.
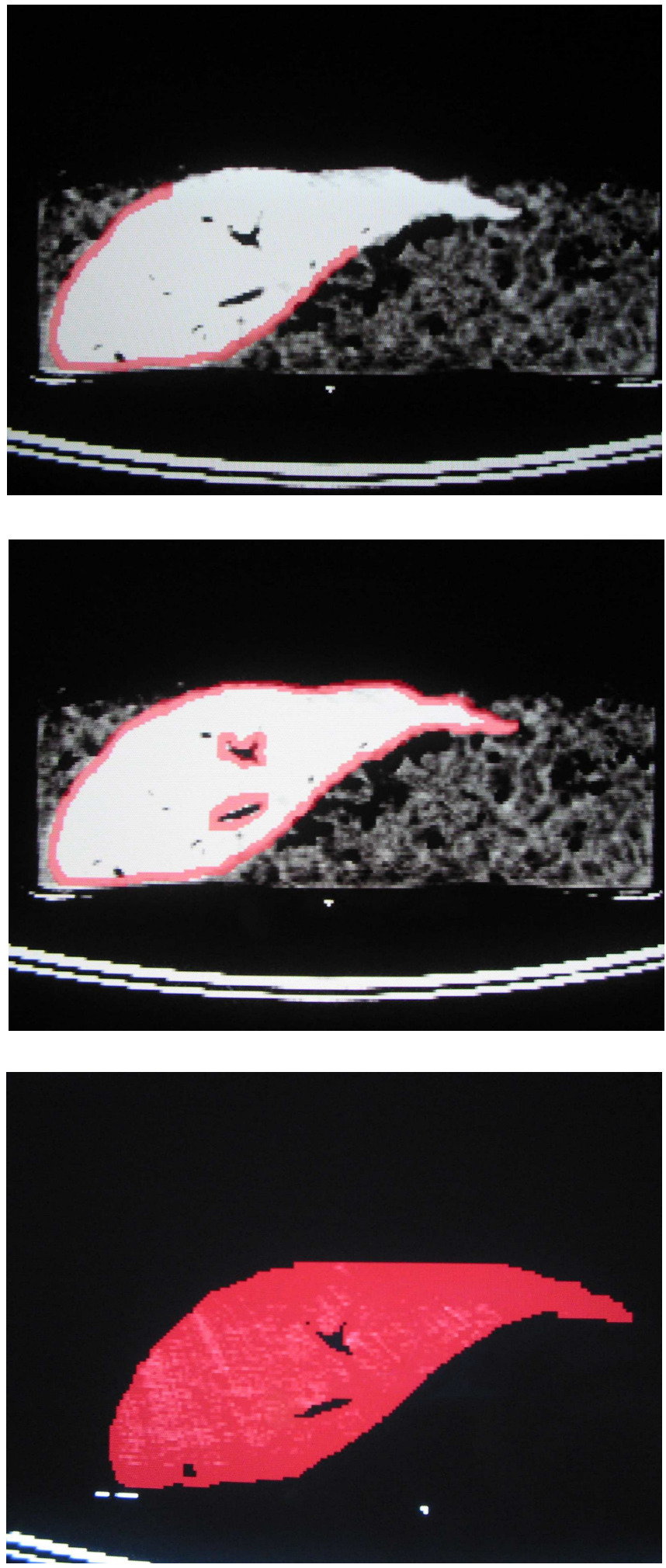

Figura 1 - Corte tomográfico de peça de hepatectomia acondicionada em recipiente plástico e envolta por gelo picado sendo avaliada pelo programa HEPATO ${ }^{\circledR}$. 
Inicialmente, para cada uma das variáveis do estudo, testou-se a hipótese nula de resultados iguais nos três grupos de suínos (sacrifícios no $5^{\circ} \mathrm{dia}$, no $10^{\circ}$ dia e no $15^{\circ} \mathrm{dia}$ ), versus a hipótese alternativa de resultados diferentes. Em seguida, em cada um dos grupos, para peso do animal, peso do fígado e volume da peça, testou-se a hipótese nula de resultados iguais no momento inicial e no momento do sacrifício, versus a hipótese alternativa de resultados diferentes.

\section{RESULTADOS}

O peso médio inicial dos animais avaliados foi de $18,1 \mathrm{~kg} \pm 2,07$. As médias dos pesos pré-operatório e no dia do sacrifício (final), para cada grupo, estão apresentadas na tabela 1. Não foi evidenciado diferença estatisticamente significativa entre os grupos. No grupo G5 houve perda de peso ponderal entre o pré-operatório e o dia do sacrifício, e nos grupos de maior duração (G10 e G15) houve aumento dele.

A média de peso (gramas) e do volume $\left(\mathrm{cm}^{2}\right)$ do fígado ressecado durante a hepatectomia foram analisados entre os grupos, não havendo diferença estatística significativa. O valor médio da porcentagem de ressecção foi analisado entre os grupos quanto à similaridade do procedimento cirúrgico realizado. Os dados revelam não haver diferença estatística entre os grupos, confirmando que a hepatectomia parcial do lobo direito realizada foi equânime nos grupos G5, G10 e G15 (Tabela 2).

A tabela 3 mostra as médias dos pesos totais dos fígados no pré-operatório e no dia do sacrifício (regenerado), bem como o porcentual de regeneração para cada grupo calculado através do peso. A média de peso do fígado no pré-operatório, em gramas, no grupo G5 foi compa- rativamente superior aos grupos $\mathrm{G} 10$ e G15. Porém, não se constatou diferença estatística significativa intergrupos. A média de peso do fígado regenerado teve pequena variação entre os grupos, não havendo diferença estatística significativa. A regeneração hepática a partir do peso do fígado (relação entre o peso no pré-operatório e peso do fígado regenerado), subdivida por grupos, revelou aumento progressivo na porcentagem da regeneração hepática entre os grupos G5 (83,58\%), G10 (94,95\%) e G15 (101,63\%). No entanto, não houve diferença estatística significativa entre as porcentagens de regeneração entre os 3 grupos $(p=0,197)$.

Observando-se os valores do volume estimado do fígado no pré-operatório, aferido em $\mathrm{cm}^{2}$, nota-se que o grupo $\mathrm{G} 15$ teve volume total menor $\left(\mathrm{G} 15=459,55 \mathrm{~cm}^{2}\right)$ que os demais grupos ( $G 5=547,12 \mathrm{~cm}^{2}$ e $\mathrm{G} 10=519,11$ $\mathrm{cm}^{2}$ ). No entanto, a análise estatística não demonstrou diferenças significativas entre esses valores. Com relação ao volume total do fígado após a regeneração hepática, houve aumento progressivo dos valores encontrados nos grupos G5 $\left(403,58 \mathrm{~cm}^{2}\right)$, G10 $\left(450,88 \mathrm{~cm}^{2}\right)$ e G15 $\left(458,93 \mathrm{~cm}^{2}\right)$, respectivamente. Esta diferença progressiva, não obteve significância estatística. A regeneração hepática a partir do peso do fígado (relação entre o peso no pré-operatório e peso do fígado regenerado), subdivida por grupos, revelou aumento progressivo na porcentagem da regeneração hepática entre os grupos G5 (74,25\%), G10 (88\%) e G15 (100\%). No entanto, não houve diferença estatística significativa entre as porcentagens de regeneração entre os 3 grupos ( $p=0,326$ ) (Tabela 4).

A comparação dos resultados da regeneração, tomando como base o peso do fígado em relação à regeneração aferida pelo volume hepático demonstrou que não há diferença estatística significativa entre os métodos (Tabela 5).

Tabela 1 - Média dos pesos pré-operatório e final dos grupos de estudo.

\begin{tabular}{llcc}
\hline & Peso pré-operatório(Kg) & Peso final $(\mathrm{Kg})$ & Valor de $\mathbf{p}$ \\
\cline { 2 - 4 } Grupo & Média+ DP & Média+ DP & 0,250 \\
G5 & $19,25 \pm 2,56$ & $18,23 \pm 1,63$ & 0,250 \\
G10 & $17,30 \pm 2,23$ & $18,05 \pm 2,30$ & 0,125 \\
G15 & $17,50 \pm 1,41$ & $18,33 \pm 1,94$ & \\
Valor de $p$ & $p=0,458$ & $p=0,968$ & \\
\hline
\end{tabular}

$D P=$ Desvio Padrão; Kg=quilogramas.

Tabela 2 - Comparação entre peso, volume e porcentagem do fígado ressecado durante a hepatectomia.

\begin{tabular}{|c|c|c|c|}
\hline & Peso (g) & Volume $\left(\mathrm{cm}^{2}\right)$ & Ressecção \\
\hline Grupo & Média+DP & Média+DP & $\%$ \\
\hline G5 & $162,75 \pm 27,72$ & $169,43 \pm 11,40$ & $31,04 \pm 2,37$ \\
\hline G10 & $150,25 \pm 59,96$ & $161,40 \pm 51,10$ & $31,00 \pm 8,68$ \\
\hline G15 & $\begin{array}{l}157,50 \pm 19,12 \\
p=0,632\end{array}$ & $\begin{array}{l}151,15 \pm 18,73 \\
p=0,535\end{array}$ & $\begin{array}{l}33,25 \pm 6,24 \\
p=0,697\end{array}$ \\
\hline
\end{tabular}

$D P=$ Desvio Padrão; $g=$ gramas; $\mathrm{cm}^{3}=$ centímetros cúbicos. 


\section{DISCUSSÃO}

A necessidade de estudos da anatomia hepática anteriormente ao transplante hepático intervivos é notória e indispensável ao planejamento cirúrgico, implicando diretamente nos resultados desse procedimento.

Segundo Kwon et al os doadores selecionados para o transplante intervivos, adulto ou pediátrico, são submetidos a procedimento cirúrgico que pode trazer diversas complicações, sendo, a mais temida, a insuficiência hepática, seguida de óbito do doador. Assim, a necessidade de conhecer o comportamento regenerativo do fígado após procedimento cirúrgico de grande porte, como a lobectomia direita, é imprescindível para se garantir a segurança, a saúde e o bem estar do doador do transplante hepático intervivos.

O desenvolvimento de técnicas para aferição do volume do fígado foi conseqüência da evolução dos apareIhos de tomografia axial computadorizada e do aumento na qualidade da aquisição de imagens, o que possibilitou as reconstruções tridimensionais das mesmas.
Desta forma, o estudo do volume hepático prétransplante intervivos se tornou rotina em todos os serviços que realizam esse procedimento ${ }^{2}$.

O método manual foi inicialmente desenvolvido para aferição volumétrica através das imagens tomográficas. Este método consiste em selecionar a área a ser avaliada por contornos realizados pelo mouse e posteriormente medir o maior diâmetro da imagem aferindose o volume a partir deste dado. 0 tempo médio de 30 minutos, despendido para contornar as imagens inviabilizava a utilização do método na prática diária. O volume hepático calculado a partir de imagens tomográficas bidimensionais pode ser interpretado de forma errônea por considerar apenas duas dimensões para o cálculo. Kawasaki et a ${ }^{8}$ propuseram a utilização de apenas uma imagem tomográfica para se calcular o volume hepático, diminuindo assim o tempo gasto para a aquisição dos dados. No entanto, este método tornou-se inviável pela percepção de que a aferição do volume a partir de um só corte tomográfico bidimensional implica em assumir que o fígado tem conformação idêntica em todos os

Tabela 3 - Peso total do fígado no pré-operatório e no dia do sacrifício e porcentagem de regeneração calculada pelo peso do órgão.

\begin{tabular}{lccc}
\hline & Fígado no pré-operatório $(\mathbf{g})$ & Fígado regenerado $(\mathrm{g})$ & \multicolumn{2}{c}{ Regeneração } \\
Grupo & Média+ DP & Média+ DP & 83,58 \\
\hline G5 & $523,25 \pm 69,66$ & $434,50 \pm 51,53$ & 94,95 \\
G10 & $470,00 \pm 60,51$ & $449,25 \pm 123,36$ & 101,63 \\
G15 & $475,25 \pm 38,66$ & $486,50 \pm 98,46$ & $p=0,197$ \\
& $p=0,458$ & $p=0,592$ & \\
\hline
\end{tabular}

$D P=$ Desvio Padrão; $g=$ gramas

Tabela 4 - Volume total do fígado no pré-operatório e no dia do sacrifício e porcentagem de regeneração calculada pelo volume do órgão.

\begin{tabular}{lccc}
\hline & Fígado no pré-operatório $(\mathbf{g})$ & Fígado regenerado $\left(\mathrm{cm}^{3}\right)$ & \multicolumn{2}{c}{ Regeneração } \\
Grupo & Média+ DP & Média+ DP & 74,25 \\
\hline G5 & $547,12 \pm 38,28$ & $403,58 \pm 43,63$ & 88 \\
G10 & $519,11 \pm 72,87$ & $450,88 \pm 104,61$ & 100 \\
G15 & $459,55 \pm 40,55$ & $458,93 \pm 100,12$ & $\mathrm{p}=0,326$ \\
& $\mathrm{p}=0,063$ & $\mathrm{p}=0,941$ & \\
\hline
\end{tabular}

$D P=$ Desvio Padrão; $\mathrm{cm}^{3}=$ centímetros cúbicos

Tabela 5 - Comparação estatística entre a regeneração hepática calculada a partir do peso hepático (fórmulas) e a calculada a partir do volume hepático estimado pelo programa HEPATO ${ }^{\circledR}$.

\begin{tabular}{lccc}
\hline \multicolumn{4}{c}{ Porcentagem de regeneração hepática após hepatectomia parcial } \\
\hline Grupos & Aferida pelo peso & Aferida pelo volume & Comparação \\
G5 & $\%$ & $\%$ & 0,465 \\
G10 & 83,58 & 74,25 & 0,144 \\
G15 & 94,95 & 88 & 0,855 \\
\hline
\end{tabular}


outros cortes adquiridos, o que deturpa a medida exata do volume hepático.

Com as desvantagens do método manual de cálculo do volume hepático, passaram a destacar-se os métodos computadorizados semi-automáticos de aferição volumétrica, a partir de imagens tomográficas ${ }^{3,9}$. Estes métodos utilizam-se de programas informatizados multiplataforma para tratar e selecionar as imagens tomográficas adquiridas e, posteriormente, calcular semiautomaticamente o volume, facilitando a prática clínica diária com o uso destas informações 6 .

No presente estudo utilizou-se um programa informatizado denominado HEPATO ${ }^{\circledR}$, desenvolvido pelo CRLC, Montpellier, França. Este software foi escolhido para ser utilizado no estudo pela facilidade de manuseio e acurácia na aferição do volume hepático.

Vários estudos demonstraram a importância do acompanhamento da regeneração hepática, tendo em vista a necessidade de analisar a resposta fisiológica, póstransplante hepático intervivos, no doador e no receptor. O desenvolvimento de métodos de estudo da volumetria hepática aferida por tomografia axial computadorizada permitiu extenso aprimoramento dos conhecimentos sobre a evolução da regeneração do parênquima hepático ${ }^{10-12}$.

Os modelos experimentais em animais tiveram papel singular no desenvolvimento dos estudos sobre a regeneração hepática, permitindo a adequação de técnicas de mensuração da regeneração.

Os primeiros estudos sobre a regeneração hepática realizados em suínos, utilizavam métodos experimentais onde analizava-se a resposta à atividade da timidina quinase, enzima responsável pela síntese de DNA nas células hepáticas, para avaliar a regeneração hepática ${ }^{13,14}$. Apesar de serem métodos fidedignos para o acompanhamento da regeneração hepática, os marcadores como a timidina quinase e a citometria de fluxo não têm a praticidade operacional necessária para a utilização na prática diária. A partir do desenvolvimento da tomografia axial computadorizada vislumbrou-se a possibilidade real de surgimento de um método capaz de ser prático e eficaz para aferição da regeneração em estudos experimentais e clínicos.

Lee et $a^{15}$ avaliaram a efetividade da crioablação de lesões hepáticas em suínos através das imagens tomográficas. Frericks et $a^{16}$ analisaram a volumetria hepática em suínos comparando-a ao deslocamento de água provocado pelo fígado suíno e os dados adquiridos por tomografia axial computadorizada. A conclusão do estudo não revelou diferença estatística entre os métodos.

O uso da tomografia axial computadorizada para avaliação da regeneração hepática em suínos após hepatectomia de $70 \%$ do parênquima hepático revelou reestabelecimento do volume hepático inicial após três semanas de pós-operatório ${ }^{17}$.

No presente estudo, a regeneração hepática após a hepatectomia realizada foi progressiva em rela- ção ao dia de pós-operatório analisado. Para se avaliar esta progressão utilizou-se dois critérios: peso e volume do fígado regenerado. O resultado confirma similaridade na evolução da regeneração hepática em todos os grupos, considerando-se as duas variáveis analisadas. O estudo demonstra também, que em valores percentuais, o grupo $\mathrm{G} 15$ teve regeneração hepática praticamente de $100 \%$, analisando-se variável peso e volume. Desta forma, após 15 dias de pós-operatório a regeneração hepática foi completa. No entanto, os outros dois grupos tiveram taxa de regeneração hepática alta, variando de 74 a $83 \%$ no G5 e 88 a $94 \%$ no G10. Esta variação dependeu da variável analisada, volume e peso respectivamente.

Em seres humanos a taxa de regeneração hepática é mais lenta que nos modelos experimentais. Ela após o transplante hepático intervivos se dá de forma diferente no receptor e no doador ${ }^{18}$. Marcos et al. ${ }^{19}$ compararam a regeneração hepática entre os receptores e os doadores do transplante hepático intervivos adulto. A taxa de regeneração após 30 dias foi maior nos doadores (144\%) do que nos receptores $(94 \%)$, em relação ao volume do fígado logo após o transplante.

No presente estudo realizou-se a comparação das taxas de regeneração hepática, em porcentagem, entre as duas variáveis utilizadas para como parâmetro de regeneração: o peso e o volume do fígado regenerado. De acordo com Lemke et al' o peso só pode ser comparado ao volume quando utiliza-se a densidade da água como fator comparativo. Isto é possível através da aferição do deslocamento de água causado pela colocação de um objeto em um recipiente cheio de água e com volume conhecido. Desta forma, pode-se considerar o peso igual ao volume (densidade da água $=1 \mathrm{~g} / \mathrm{mL}$ ). A maioria dos estudos utiliza-se destes elementos para comparar peso e volume do fígado regenerado.

Aqui demonstra-se a possibilidade de se comparar as porcentagens de regeneração hepática, a partir das variáveis peso e volume, através de estudo estatístico, para se confirmar a fidedignidade dos resultados achados pela volumetria hepática por tomografia axial computadorizada e o peso do fígado regenerado. Desta forma, o estudo revelou que não houve diferença estatística significativa entre os resultados das duas variáveis, independentemente dos grupos de animais estudados.

Os resultados do presente estudo permitiram concluir que a utilização da tomografia axial computadorizada para análise da volumetria hepática, a partir de um programa de aquisição e processamento semi-automático de imagens digitalizadas, é parâmetro fidedigno para acompanhamento e avaliação da regeneração hepática em suínos. As taxas percentuais de regeneração hepática, aferidas pelo peso do fígado regenerado foram estatisticamente iguais às aferidas pelo volume hepático por tomografia axial computadorizada. 


\title{
A
}

\begin{abstract}
Objectives: To analyze the hepatic volume by computerized tomography using a semiautomatic computerized program of acquisition and processing digitalized images, to follow the hepatic regeneration in swine after partial hepatectomy. Methods: Twelve female young Landrace swine were separated in three groups according to the observation time between hepatectomy and sacrifice: G5 (5 days), G10 (10 days) and G15 (15 days). All animals were submitted to partial hepatectomy of the right lobe and followed until sacrifice, when regenerated liver was ressected. The surgical piece and the regenerated liver were weighted and submitted to tomographic volume evaluation by the software HEPATO ${ }^{\circledR}$, taking place acquisition and analysis of the tomography images in a semiautomatic way. Statistical analysis used the non-parametric Kruskal-Wallis and Wilcoxon tests. Results: Medium weigh of regenerated liver was $G 5=434,5 \mathrm{~g}, G 10=449,25 \mathrm{~g}$ and $\mathrm{G} 15=486,5 \mathrm{~g}(\mathrm{p}=0,592)$. The regeneration index obtained using liver weight was $83,58 \%(G 5), 94,95 \%$ (G10) and 101,63\% (G15) ( $p=0,197)$. Medium volume of regenerated liver was $G 5=403,58 \mathrm{~cm}^{2}$ $G 10=450,88 \mathrm{~cm}^{2}$ and $G 15=458,93 \mathrm{~cm}^{2}(p=0,941)$. Liver regeneration index obtained using liver volume was $74,25 \%(G 5), 88 \%(G 10)$ and $100 \%(G 15)(p=0,326)$. Liver regeneration index was not different when assessed using liver weigh or liver volume. Conclusion: The liver volumetric evaluation by computerized tomography using a computerized semiautomatic program of digitalized images acquisition and processing is a trustworthy method for evaluation and following the liver regeneration in swine after partial hepatectomy.
\end{abstract}

Key words: Liver regeneration. Tomography. Hepatectomy. Swine.

\section{REFERENCIAS}

1. Lemke AJ, Brinkmann MJ, Schott T, Niehues SM, Settmacher U, Neuhaus P, Felix R. Living donor right liver lobes: preoperative CT volumetric measurement for calculation of intraoperative wheigt and volume. Radiology. 2006; 240(3):736-42. Epub 2006 Jul 25.

2. Schiano TD, Bodian C, Schwartz ME, Glajchen N, Min AD. Accuracy and significance of computed tomographic scan assessment of hepatic volume in patients undergoing liver transplantation. Transplantation. 2000; 69(4):545-50.

3. Soler L, Dellingette $H$, Malandain G, Montagnat J, Ayache N, Koehl $C$, et al. Fully automatic anatomical, pathological, and functional segmentation from CT scans for hepatic surgery. Comput Aided Surg. 2001; 6(3):131-42.

4. Kahn D, Hickman R, Terblanche J. A porcine model for the study of liver regeneration. J Invest Surg. 1988; 1(2):139-42.

5. Vãn Minh T. Anatomic basis of pig liver partition for experimental transplantation e perspective in xenotransplantation. Transplant Proc. 1996; 28(1):61-2

6. Chemouny $S$, Joyeux $H$, Masson $B$, Borne $F$, Jaeger $M$, Monga $O$. Advanced 3D image processing techniques for liver and hepatic tumors location and volumetry. Medical Imaging. 1999;121(3):2346.

7. Kwon KH, Kim YW, Kim SI, Kim KS, Lee WJ, Choi JS. Postoperative liver regeneration and complication in live liver donor after partial hepatectomy for living donor liver transplantation. Yonsei Med J. 2003; 44(6):1069-77

8. Kawasaki S, Makuuchi M, Matsunami $H$, Hashikura $Y$, Ikegami T, Chisuwa $\mathrm{H}$, et al. Preoperative measurement of segmental liver volume of donors for living related liver transplantation. Hepatology. 1993: 18(5):1115-20

9. Zanchet DJ, Montero EF, Marques AM, Dietrich CA, Nedel LP. Personal computer software evaluation intreractive generation of pig liver three-dimensional anatomical images. Transplant Proc. 2005; 37(1): 198-200.

10. Chari RS, Baker ME, Sue SR, Meyers WC. Regeneration of a transplanted liver after right hepatic lobectomy. Liver Transpl Surg 1996: 2(3):233-4

11. Gondolesi GE, Yoshizumi T, Bodian C, Kim-Schluger L, Schiano T, Fishbein T, Schwartz M, Miller C, Emre S. Accurate method for clinical assessment of right lobe liver weight in adult living-related liver transplant. Transplant Proc. 2004; 36(5):1429-33.
12. Yokoy H, Isaji S, Yamagiwa K, Tabata M, Sakurai H, Usui M, Mizuno $S$, Uemoto $S$. Donor outcome and liver regeneration after rightlobe graft donation. Transpl Int. 2005; 18(8):915-22.

13. Chow PK, Jeyaraj P, Tan SY, Cheong SF, Soo KC. Serial ultrasound-guided percutaneous liver biopsy in a partial hepatectomy porcine model: a new technique in the study of liver regeneration. J Surg Res. 1997; 70(2):134-7.

14. Sun L, Chow PK, Fook-Chong SM, Chew M, Aw SE, Soo KC. Liver regeneration after partial hepatectomy is non-uniform: flow cytometric bromodeoxyuridine incorpopration and cell cycle studies in a porcine model. Res Exp Med (Berl). 1999; 198(5):229-36.

15. Lee FT Jr, Chosy SG, Littrup PJ, Warner TF, Kuhlman JE, Mahvi DM. CT-monitored percutaneous cryoablation in a pig liver model: pilot study. Radiology. 1999; 211(3):687-92.

16. Frericks BB, Kiene T, Stamm G, Shin H, Galanski M. [CT-based liver volumetry in a porcine model: impact on clinical volumetry prior to living donated liver transplantation]. Rofo. 2004; 176(2):252-7.

17. Court FG, Laws PE, Morrison CP, Teague BD, Metcalfe MS, Wemyss-Holden SA, Dennison AR, Maddern GJ. Subtotal hepatectomy: a porcine model for the study of liver regeneration. J Surg Res. 2004; 116(1):181-6.

18. Kawasaki S, Makuuchi M, Ishizone $S$, Matsunami $H$, Terada $M$, Kawarazaki $\mathrm{H}$. Liver regeneration in recipients and donors after transplantation. Lancet. 1992; 339(8793):580-1.

19. Marcos A, Fisher RA, Ham JM, Shiffman ML, Sanyal AJ, Luketic VA, Sterling RK, Fulcher AS, Posner MP. Liver regeneration and function in donor and recipient after right lobe adult to adult living donor liver transplantation. Transplantation. 2000; 69(7):1375-9.

Recebido em 03/09/2008

Aceito para publicação em 05/11/2008

Conflito de interesse: nenhum

Fonte de financiamento: nenhuma

\section{Como citar este artigo:}

Carvalho FA, Joyeux H, Coelho JCU, Sain-Aubert B, Rouanet P, Matias JEF. Volumetria hepática computadorizada como método de avaliação e acompanhamento da regeneração hepática após hepatectomia parcial em suínos. Rev Col Bras Cir. [periódico na Internet] 2009; 36(1). Disponível em URL:http://www.scielo.br/rcbc

\section{Endereço para correspondência:}

Jorge Eduardo Fouto Matias

E-mail: jefmatias@ufpr.br 